\title{
Preintercalation of an organic accelerator into nanogalleries and preparation of ethylene propylene diene terpolymer rubber-clay nanocomposites
}

\author{
Sandip Rooj ${ }^{1}$, Amit Das $^{1}$ and Gert Heinrich ${ }^{1,2}$ \\ A multifunctional additive, bis(diisopropyl) thiophosphoryl diisopropyl disulfide (DIPDIS), was melted in the presence of \\ quaternary ammonium-modified montmorillonite clay and incorporated into an ethylene propylene diene terpolymer (EPDM) \\ rubber matrix as a nanofiller to prepare EPDM rubber nanocomposites. The finer dispersion of the organoclay (OC) in the rubber \\ matrix was observed when the OC was preintercalated by DIPDIS using the propping-open procedure. X-ray diffraction (XRD) \\ results showed that the silicate layers of the OC were successfully preintercalated by the DIPDIS; that is, the basal spacing of \\ clay galleries was expanded from 2.98 to $3.76 \mathrm{~nm}$. Because of the larger interlayer distance, as evidenced by XRD studies, the \\ delamination process was facilitated through the easy intercalation of macromolecular rubber chains, which was reflected in \\ various properties, such as the stress-strain behavior, thermal stability, dynamic mechanical properties and swelling properties. \\ XRD studies and transmission electron microscopy directly supported the effective filler dispersion in the non-polar EPDM \\ rubber matrix.
}

Polymer Journal (2011) 43, 285-292; doi:10.1038/pj.2010.132; published online 26 January 2011

Keywords: DIPDIS; montmorillonite; multifunctional additive; propping-open procedure

\section{INTRODUCTION}

Polymer nanocomposites based on nanoclay have recently generated a great deal of interest as a successful approach to overcome the inadequacy of conventional composites. ${ }^{1-4}$ Very recently, advances in rubber-clay nanocomposites have attracted the attention of scientists working in the field of polymer-clay nanocomposites. In addition to higher gas barrier properties and certain improved fireresistance properties, most of the developed rubber-clay nanocomposites exhibit much higher tensile strength than that of the corresponding matrix. Generally, the corresponding ratio is at least two to three times greater. ${ }^{5,6}$ However, because of the inorganic nature of the clay minerals, the dispersion by the delamination process of the clay layers is the main problem for the desirable reinforcement of the silicate clay layers. The most established and common ways to overcome this problem are the use of quaternary ammonium salt, ${ }^{7}$ surfactants, ${ }^{8,9}$ ionic liquids, ${ }^{10,11}$ silane coupling agents ${ }^{12,13}$ and different fatty acid salts, ${ }^{14}$ which are common approaches to obtain a higher degree of delamination. Very recently, it was reported that ${ }^{15}$ the preintercalation of stearic acid into the gallery of layered silicate, which was already modified by quaternary ammonium compounds (QUATs), could be one common approach to make the delamination process more effective. The effectiveness of this process was verified in different rubber systems where crosslinking was caused by a sulfur vulcanization process. In another work, stearic acid intercalated clay was successfully applied to obtain the compatible rubber blend of two dissimilar rubbers: polychloroprene and ethylene propylene diene terpolymer (EPDM). ${ }^{16}$ The physical properties were improved significantly, which was understood by an unusual thermodynamically driven network formation of exfoliated clay particles at the interface. The effect of the stearic acid induced delaminated structure of the clay on the mechanical performance of natural rubber compounds was also reported. ${ }^{17}$ In all three cases, premixing the stearic acid with OC served to swell the clay layers, which further allowed the rubber molecules to penetrate more easily into the layer space.

On the other hand, bis(dialkyl)thiophosphoryl disulfides have been used extensively in many industrial applications, such as insecticides, ${ }^{18}$ ultraviolet stabilizers ${ }^{19}$ and antioxidants, since their identification in 1925. ${ }^{20}$ The use of bis(diisopropyl) thiophosphoryl diisopropyl disulfide (DIPDIS) as an accelerator for rubber vulcanization was first described by Romieux. ${ }^{21}$ Since then, interest has been limited to natural rubber applications. Pimblott et al. studied in detail the effect of DIPDIS as a curative for infrared rubber. ${ }^{22}$ It had been observed by earlier researchers that DIPDIS can also function as a coupling agent for silica-filled EPDM compounds analogous to silanes. ${ }^{23}$ It was also established that interfacial chemical bonding could be caused by DIPDIS. ${ }^{24-27}$ The crosslinking activity of different thiophosphoryl

${ }^{1}$ Leibniz-Institut für Polymerforschung Dresden e. V., Dresden, Germany and ${ }^{2}$ Institut für Werkstoffwissenschaft, Technische Universität Dresden, Dresden, Germany Correspondence: Dr A Das, Leibniz-Institut für Polymerforschung Dresden e. V., Hohe Strasse 6, Dresden 01069, Germany. E-mail: das@ipfdd.de

Received 10 August 2010; revised 8 November 2010; accepted 12 November 2010; published online 26 January 2011 
compounds even on polychloroprene rubber has been also established. ${ }^{28}$ It is clear from this literature survey that DIPDIS can serve as a multifunctional additive by providing the following activities: (i) an accelerator for sulfur vulcanization systems, (ii) a coupling agent such as silane in silica-filled elastomeric systems, (iii) a crosslinking agent for chloroprene rubber and (iv) a compatibilizer as well as covulcanization agent for different rubber blends. Bis(dialkyl) thiophosphoryl disulfides are prepared by the oxidation of dialkyl phosphorodithioic acid, and the general formula of this type of compound is:

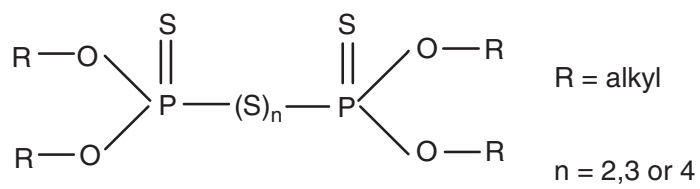

This study reports, for the first time, the utilization of DIPDIS as a multifunctional rubber additive in the preparation of rubber-clay nanocomposites using a two step mixing process. After the successful preintercalation of $\mathrm{OC}$ in the first step with this additive utilizing propping-open procedure, ${ }^{29}$ it was used as an accelerator as well as nanofiller for the preparation of EPDM nanocomposites in the second stage. The mechanical and dynamic properties and the morphology of various EPDM nanocomposites were characterized.

\section{EXPERIMENTAL PROCEDURE}

\section{Materials}

Buna EP G 6850, the ethylidene norbornene-containing EPDM rubber, was obtained from Lanxess (Leverkusen, Germany). The EPDM contained $51 \mathrm{wt} \%$ of ethylene and $7.7 \mathrm{wt} \%$ of ethylidene norbornene. It had a Mooney viscosity, ML (1+4), of 60 at $125^{\circ} \mathrm{C}$ and a density of $0.860 \mathrm{~g} \mathrm{~cm}^{-3}$. The stearic acid was purchased from ACROS Organics (Geel, Belgium) with $97 \%$ purity. The sulfur (S) and zinc oxide $(\mathrm{ZnO})$ used in this study were industrial grades. DIPDIS was synthesized in our laboratory according to the method of Pimboltt et al. ${ }^{22}$ The distearyl dimethyl ammonium chloride modified clay (Nanofil-15) was supplied by Süd-Chemie AG (Moosburg, Germany).

\section{Preparation of nanocomposites}

The preintercalation of OC by DIPDIS was carried out in the following way. The DIPDIS and the OC were placed in a porcelain mortar and mixed with a pestle. The ratio of DIPDIS and OC was 3.83:5. Then, the mortar with the mixture was kept in an oven at $100{ }^{\circ} \mathrm{C}$ for $15 \mathrm{~min}$. The mixture was then homogenized thoroughly by using the pestle. Again, the mortar was heated to $100^{\circ} \mathrm{C}$, followed by homogenization. To obtain a very homogeneous mixture, the process was repeated three times. In this article, the organoclay and preintercalated organoclay are termed as OC and IOC, respectively.

Table 1 Formulations and curing characteristics

\begin{tabular}{|c|c|c|c|c|}
\hline Compounds ${ }^{\mathrm{a}}$ & $E P D M$ & $E P-O C$ & $E P-I O C$ & $E P-Q U A T$ \\
\hline EPDM & 100 & 100 & 100 & 100 \\
\hline $\mathrm{ZnO}$ & 5 & 5 & 5 & 5 \\
\hline Stearic acid & 2 & 2 & 2 & 2 \\
\hline $\mathrm{OC}$ & - & 5 & - & - \\
\hline IOC & - & - & 8.83 (5 OC+3.83 DIPDIS) & - \\
\hline DIPDIS & 3.83 & 3.83 & - & - \\
\hline S & 1 & 1 & 1 & 1 \\
\hline QUAT & - & - & - & 1 \\
\hline Scorch time, $t_{2}$ (min) & 6.80 & 2.06 & 2.00 & 0.48 \\
\hline Curing time, $t_{90}(\mathrm{~min})$ & 38.05 & 14.72 & 17.16 & 3.50 \\
\hline
\end{tabular}

Abbreviations: EPDM, ethylene propylene diene terpolymer; IOC, intercalated organoclay; OC, organoclay; QUAT, quaternary ammonium salt; S, sulfur; ZnO, zinc oxide.

aThe weight of the ingredients were taken in parts per hundred of rubber.
The compounding of EPDM with OC and IOC, including other ingredients such as zinc oxide $(\mathrm{ZnO})$, stearic acid, DIPDIS and sulfur (S), was performed in a laboratory-sized two-roll mill (Polymix110L, friction ratio $=1: 1.25$, roll temperature $=40^{\circ} \mathrm{C}$ ). Table 1 shows the compositions of the modified and unmodified OC-filled EPDM rubber nanocomposites. This compounded rubber was then subjected to rheometric study to obtain the optimum cure time of the compounded rubber. The rubber samples were then cured until their optimum curing time $\left(\mathrm{t}_{90}\right)$ by a hot press at $160^{\circ} \mathrm{C}$, cooled to room temperature and kept for $48 \mathrm{~h}$ for maturation.

\section{Characterization}

Curing studies were performed using Scarabaeus SIS-V50, a rubber processing analyzer (Scarabaeus Mess-und Produktionstechnik GmbH, SIS-V50, Langgöns, Germany) in the isothermal time sweep mode for all the samples at $160{ }^{\circ} \mathrm{C}$ for $60 \mathrm{~min}$.

$\mathrm{X}$-ray diffraction (XRD) measurements were carried out with a 2-circle diffractometer XRD $3003 \theta / \theta$ (GE Inspection Technologies/Seifert-FPM, Freiberg, Germany) using $\mathrm{Cu}-\mathrm{K} \alpha$ radiation $(\lambda=0.1541 \mathrm{~nm})$ at $40 \mathrm{kV}$ and $30 \mathrm{~mA}$. The $d$-spacing of the layered particles was then calculated from Bragg's equation, $n \lambda=2 d \sin \theta$, where $\lambda$ is the wavelength of the $\mathrm{X}$-ray, $d$ is the interlayer distance and $\theta$ is the angle of incident $\mathrm{X}$-ray radiation.

The Fourier-transform infrared spectra of the composites were obtained using a BRUKER VERTEX $80 \mathrm{~V}$ spectrometer (BRUKER, Ettlingen, Germany) over the wave number range of $4000-400 \mathrm{~cm}^{-1}$ in the attenuated total reflection (ATR) mode.

Tensile tests of cured samples were carried out using a Zwick 1456 (Z010, Ulm, Germany) with a crosshead speed of $200 \mathrm{~mm} \mathrm{~min}^{-1}$ (ISO 527).

Dynamic mechanical analysis was performed on cut strips of $10 \mathrm{~mm}$ width and $35 \mathrm{~mm}$ length using a dynamic mechanical thermal spectrometer (Gabo Qualimeter, Ahlden, Germany, model Eplexor-2000N) in the tension mode. The isochronal frequency employed was $10 \mathrm{~Hz}$, and the heating rate was $2^{\circ} \mathrm{Cmin}^{-1}$.

The thermogravimetric analysis was performed using a TA TGA, Q 500 instrument (TA Instruments, New Castle, DE, USA) with a heating rate of $10^{\circ} \mathrm{C} \mathrm{min}^{-1}$ under a nitrogen atmosphere, and the sample was swept by oxygen flow at $700^{\circ} \mathrm{C}$.

The state of the dispersion of the clay particles in the nanocomposites was investigated using transmission electron microscopy (TEM) with a JEM 2010 model with an acceleration voltage of $200 \mathrm{kV}$. The ultra-thin sections $(100 \mathrm{~nm})$ of the samples were prepared by ultramicrotomy (Leica Ultracut UCT, Leica, Wetzlar, Germany) at $-120^{\circ} \mathrm{C}$.

The crosslink density of the specimens was measured on the basis of the rapid solvent-swelling measurements (toluene uptake for $72 \mathrm{~h}$ at $25^{\circ} \mathrm{C}$ ) by application of the Flory-Rehner equation: ${ }^{30}$

$$
V_{C}=\frac{1}{M_{C}}=-\frac{\ln \left(1-V_{2}\right)+V_{2}+\chi V_{2}^{2}}{V_{S} d_{r}\left(V_{2}^{1 / 3}-\frac{V_{2}}{2}\right)}
$$

where $V_{c}=$ effective crosslink density, $V_{2}=$ volume fraction of EPDM in the swollen specimen, $V_{S}=$ molar volume of the solvent, $d_{r}=$ density of the polymer, $M_{c}=$ molecular weight of the polymer between crosslinks and $\chi=$ interaction coefficient between rubber network and solvent.

\section{RESULTS AND DISCUSSION ATR spectroscopy}

The major band at $3630 \mathrm{~cm}^{-1}$ shown in Figure $1 \mathrm{can}$ be assigned to the stretching vibrations of $\mathrm{Al}-\mathrm{OH}$ corresponding to the inner hydroxyl groups lying between the tetrahedral and octahedral sheets (12). Another broad peak at $3430 \mathrm{~cm}^{-1}$ is attributed to the hydroxyl stretching vibrations (free and interlayer water molecules) in OC. The peak intensity of $3630 \mathrm{~cm}^{-1}$ decreased after modification with DIPDIS. This observation suggests that the DIPDIS molecules can intercalate the interlayer space of the OC when DIPDIS is melt-mixed in the presence of OC and interact with the free inner hydroxyl groups in the nanogallery. The plausible schematic of the chemical interactions is given in Scheme 1. A similar type of interaction was observed between silica and DIPDIS by Mandal et al. ${ }^{31}$ After the treatment with 
DIPDIS, it is expected that the interlayer space will increase, which could facilitate the intercalation of rubber chains into the clay nanogallery. A schematic diagram is represented in Scheme 1.

On the other hand, it is also expected that DIPDIS will interact with the rubber chain and the silicate particles because of its multifunctional character. Ghosh et al. ${ }^{32}$ showed an identical reaction mechanism when they treated EPDM with DIPDIS in a silica-filled system. Figure 2 shows the ATR-infrared given for EPDM-gum and EPDM-clay nanocomposites. The expected absorption bands at 667, 722 and $750 \mathrm{~cm}^{-1}$ can be assigned to the bending vibration of the $\mathrm{C}-\mathrm{H}$ bond in the (ethylidene norbornene unit of EPDM. The peaks at $1154,1375,1463$ and $2723 \mathrm{~cm}^{-1}$ correspond to the $\mathrm{C}-\mathrm{H}$ stretching vibration for the polypropylene unit present in the EPDM. ${ }^{33}$ As expected, the peak intensity corresponding to the ethylidene norbornene band decreased with the addition of pre-IOC. A prominent decrease is observed at 667 and $750 \mathrm{~cm}^{-1}$, clearly suggesting a chemical and physical interaction between EPDM and IOC, which contains grafted DIPDIS. A reaction mechanism is suggested based on the ATR-infrared spectrum and is presented in Scheme 2.

\section{Morphological study: XRD and TEM}

Because the melting point of DIPDIS is $92^{\circ} \mathrm{C}$, the preintercalation of DIPDIS was performed at $100^{\circ} \mathrm{C}$, which is well above the melting

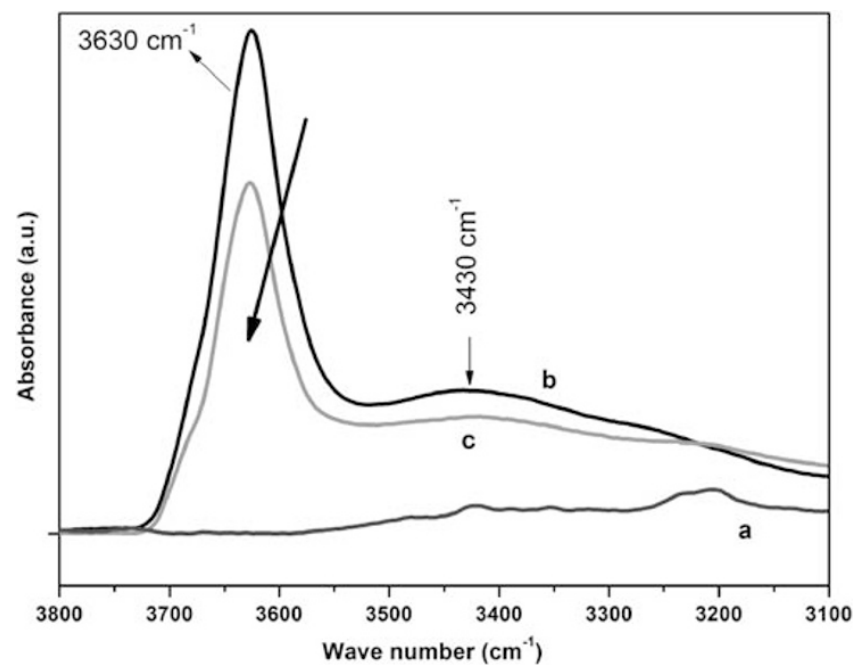

Figure 1 Attenuated total reflection-infrared spectra of (a) DIPDIS, (b) OC and (c) IOC. point of DIPDIS to favor the intercalation process. At this temperature, molecules can easily penetrate into the gallery gap of the OC, similar to the usual melt intercalation process. Figure 3 describes the XRD patterns of the OC, IOC, DIPDIS and nanocomposites. The OC showed a diffraction peak at $2 \theta=2.8^{\circ}$, which is related to the $d_{001}$ plane, whereas DIPDIS did not show any peak at low $2 \theta$ angles. This peak of the $d_{001}$ plane of OC shifted to low $2 \theta$ values when it was treated with DIPDIS at $100^{\circ} \mathrm{C}$. In the case of IOC, the basal peak appeared at $2 \theta=2.3^{\circ}$, and the corresponding basal spacing was $3.76 \mathrm{~nm}$. According to the XRD patterns, an increase of almost $1 \mathrm{~nm}$ in the gallery space was obtained when the clay was preintercalated with DIPDIS. The reduction of $2 \theta$ and the increase in the basal spacing of the IOC may be attributed to the intercalation by low molecular weight DIPDIS. The intercalation of low molecular weight organic molecules into the nanogalleries is well known and has been reported in various studies. Lagaly et $a .^{34}$ also found that the interlayer gaps of dodecylammonium modified montmorillonite increased with the increase in chain length of different alcohols. However, the increase of the gallery gap was not observed when the chain length was less than six carbon atoms. ${ }^{35}$ In this study, the chain length of the organic modifier was 18 carbon atoms. Consequently, the further increase of the basal spacing of IOC should be attributed to

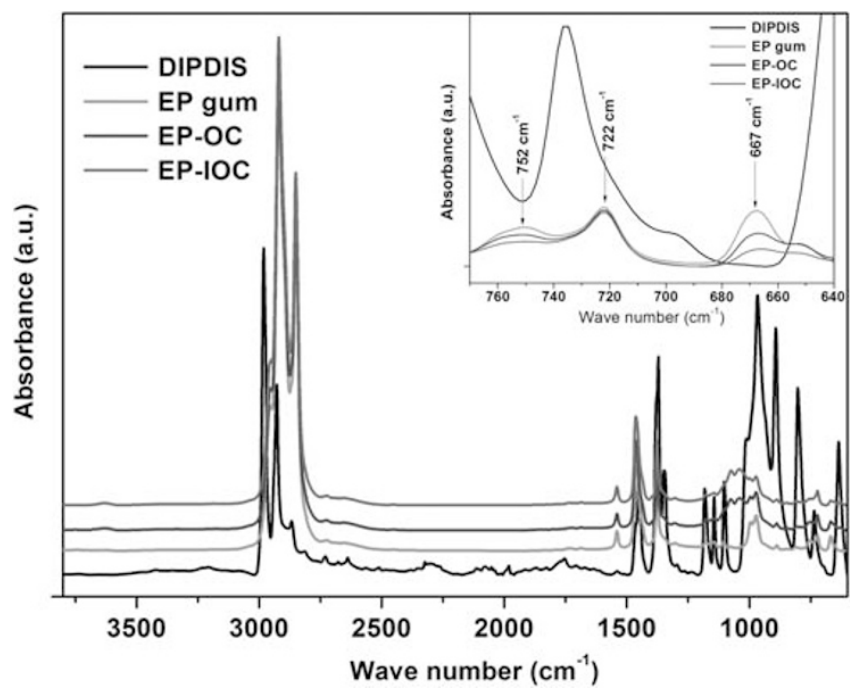

Figure 2 Attenuated total reflection-infrared spectra of DIPDIS, ethylene propylene diene terpolymer (EPDM) gum, EPDM filled with OC and EPDM filled with IOC.
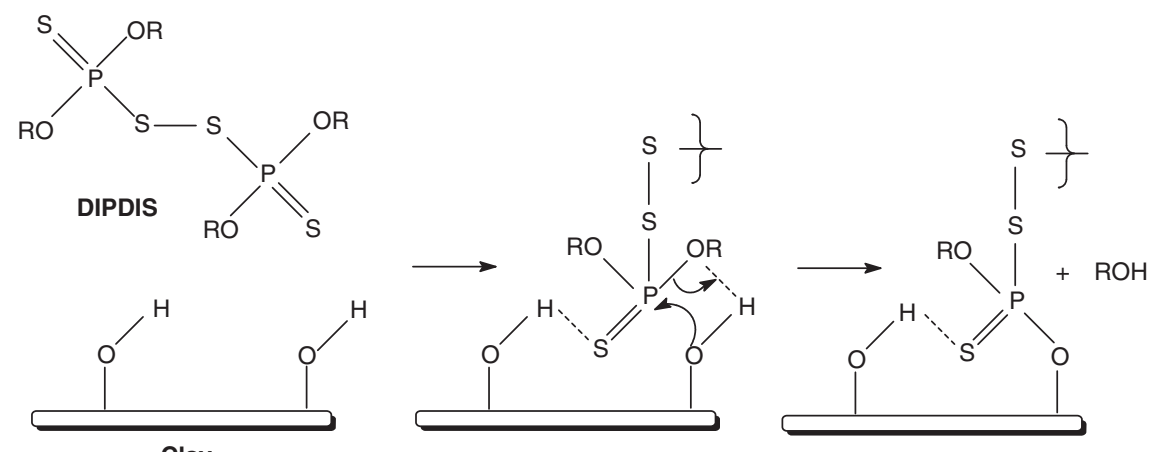

Clay

Scheme 1 Hydroxyl groups present in the clay galleries and edges can readily interact with DIPDIS molecules. 

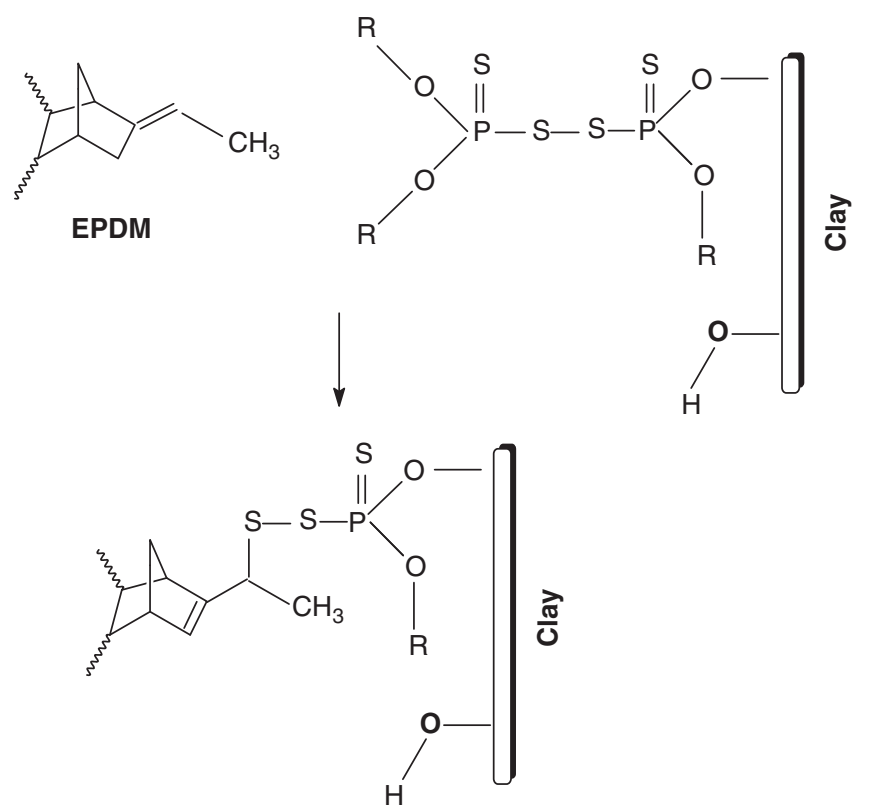

Scheme 2 DIPDIS-bound clay particles can reasonably graft at the unsaturation present in the ethylene propylene diene terpolymer (EPDM) rubber.

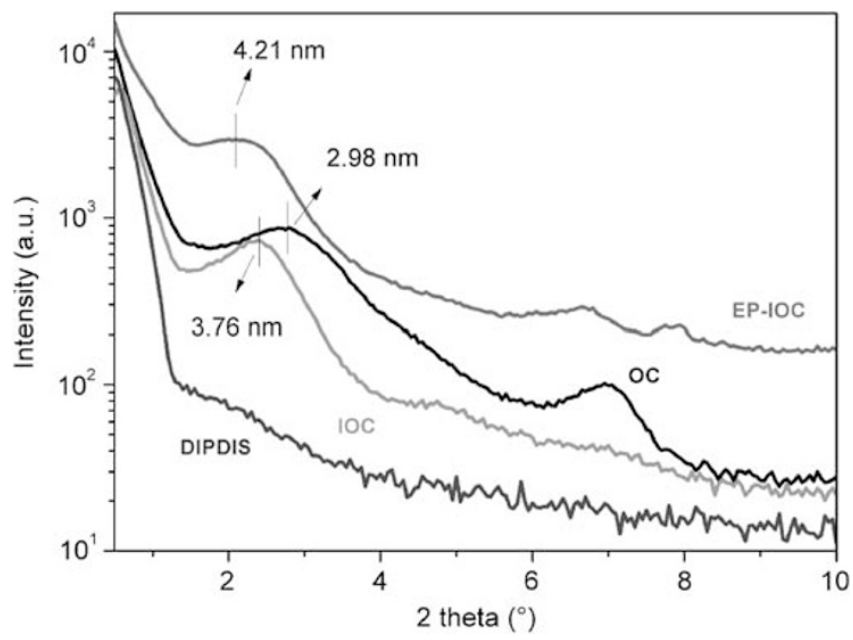

Figure 3 X-ray diffraction patterns of OC, DIPDIS, intercalated organoclay (IOC) and rubber nanocomposites containing IOC. In the modification of the organoclay, the ratio of DIPDIS/organoclay was 3.83:5. The accelerator used in the formulation was equivalent to $9 \mathrm{mmol}$ per $100 \mathrm{gm}$ of rubber.

the intercalation of DIPDIS molecules into the nanogallery of the clay layers. The Toyota group ${ }^{36}$ reported that a proper choice of a rubbervulcanizing accelerator in rubber curing packages can improve the dispersion of the layered silicate clay minerals in the rubber matrix. They found that thiuram and dithiocarbamate-type rubber accelerators can polarize the rubber chain by grafting the accelerator fragments on the backbone of the rubber chains. Using this method, an exfoliated structure of the clay particles was produced. In this study, this observation was demonstrated with the help of ATR-infrared spectroscopy. Nevertheless, a shift in the X-ray pattern at lower scattering angles in the rubber nanocomposites indicated the effective delamination of the clay layers into the rubber matrix. The plausible chemical interactions between the clay layers and DIPDIS molecules were reasonably speculated, which is given in Schemes 1 and 2. The conclusions drawn from the XRD patterns of the nanocomposites were further established by analyzing the TEM micrographs of these materials at various magnifications. The degree of dispersion or exfoliation of the clay nanolayers had an important role in the performance of the polymer nanocomposites. The micrographs are shown in Figure 4. The gray continuous phase corresponds to EPDM, and darker gray and black spots correspond to clay platelets. Figures $4 \mathrm{a}$ and $\mathrm{b}$ show that the highly dispersed clay plates are irregular in shape, and the lengths of the clay particles are between 200 and $300 \mathrm{~nm}$. The population of the delaminated structure is higher than that of the exfoliated layered platelets. At higher magnification (Figures $4 \mathrm{c}$ and $\mathrm{d}$ ), the presence of a single exfoliated layer supports the rubber-clay interaction shown in the above-mentioned scheme. Because of the presence of DIPDIS inside the clay gallery, the clay platelets directly interact with the rubber chains during the formation of chemical linkages between the rubber and clay through DIPDIS fragments, as shown in Scheme 2.

\section{Curing activity}

Figure $5 \mathrm{a}$ describes the improvement of the torque with time of the EPDM rubber compounds at $160^{\circ} \mathrm{C}$ in the presence of OC and IOC. In this case, DIPDIS was used to preintercalate the OC. DIPDIS was also used as an accelerator for the gum compound. An equivalent amount of DIPDIS was used as a modifier, and it served as a multifunctional additive. Therefore, DIPDIS can function as an OC modifier and also as an accelerator in the vulcanization process. Figure 5 shows that, after the addition of OC and IOC, the torque increased compared with that of the gum without any filler. It was found that the increase of the torque was higher for the DIPDISmodified clay, designated as EP-IOC. The slight curing reversion was also noticed for EP-OC after a long period of time, whereas EP-IOC did not suffer from reversion. The scorch time and cure time decreased for the filled system compared with gum (Table 1). It is supposed that the presence of the QUAT present in the clay layers acted as a synergistic pair with DIPDIS in terms of curing activity. To understand the synergistic curing activity between DIPDIS and QUAT, the compound EP-QUAT (Table 1) was prepared. The curing data showed that the scorch time and curing time were diminished to a significant extent in comparison to those of EP-IOC and EP-OC. This phenomenon indicates the effective combination of DIPDIS and QUAT for faster curing reactions of the EPDM compounds. Again, to ensure the multifunctional activity of DIPDIS, a standard and familiar curing accelerator, tetra methyl thiuram disulfide, was considered. The curing curve is shown in Figure 5b. After the addition of OC, the ultimate rheometric torque did not change appreciably, whereas DIPDIS showed a remarkable enhancement of the curing torque. Moreover, the curing nature of the curves slowed for the compounds cured by tetra methyl thiuram disulfide. This observation demonstrates the suitability of DIPDIS in the EPDM formulation.

Estimation of the crosslink density: stress-strain measurements The structure-property relationship was analyzed using the stressstrain behavior illustrated by a phenomenological expression suggested by Mooney ${ }^{37}$ and Rivlin and Saunders: ${ }^{38}$

$$
\frac{\sigma}{\lambda-\lambda^{-2}}=2\left(C_{1}+C_{2} \lambda^{-1}\right)
$$

where $\sigma$ is the applied stress, $\lambda$ is the extension ratio and $C_{1}$ and $C_{2}$ are the phenomenological Mooney-Rivlin (MR) constants, which can be related to the network structure and the flexibility of the network chains. $C_{1}$ is directly proportional to the number of elastically active 

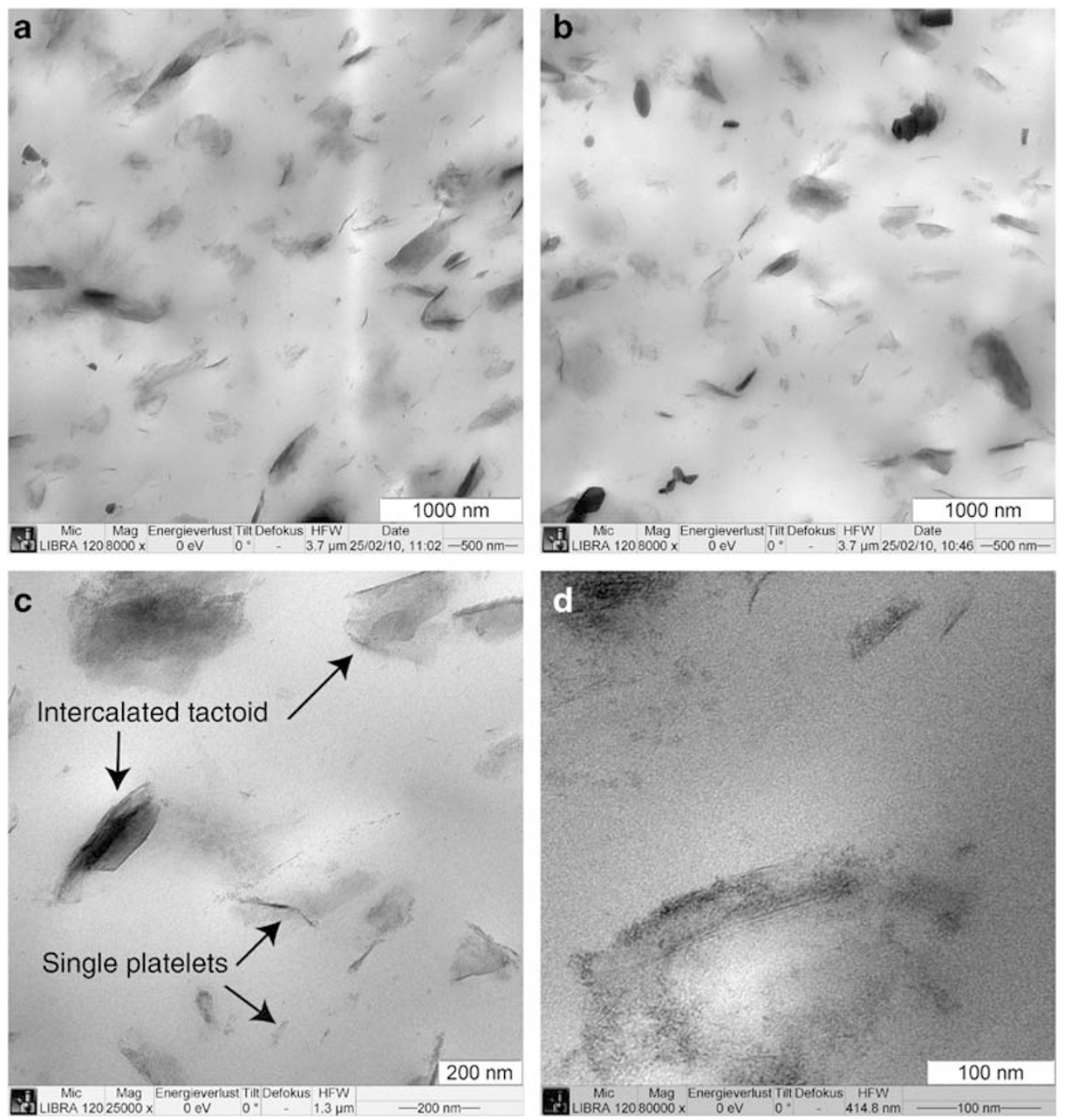

Figure 4 Transmission electron micrographs of ethylene propylene diene terpolymer (EPDM) rubber matrix containing DIPDIS intercalated clay.

network chains per unit volume of the rubber. The value of $C_{2}$ can be related to the number of the elastically effective trapped entanglements, the number of steric obstructions and other network defects. In the case of filled systems, the two latter effects provide a substantial contribution to $C_{2}$ compared with the influence of the trapped entanglements. For filled systems, the estimated or apparent crosslink density can be analyzed with the help of the MR equation under the assumption that the hard filler particles do not undergo deformation. Thus, the macroscopic strain is lower than the intrinsic strain (local elongation of the polymer matrix). Thus, in the presence of hard particles, the macroscopic strain is usually replaced by a true intrinsic strain:

$$
\lambda=1+\varepsilon X
$$

where $\varepsilon$ is the macroscopic elongation and $X$ is an amplification factor. The latter can be defined as:

$$
X=1+2.5 \varphi_{f}+14.1 \varphi_{f}^{2}
$$

where $\varphi_{f}$ is the volume fraction of the spherical filler particles. This definition is based on the well-known Guth-Gold equation: ${ }^{39}$

$$
G=G_{0}\left(1+2.5 \varphi_{f}+14.1 \varphi_{f}^{2}\right)
$$

where $G_{0}$ is the modulus of the matrix. This equation is based on Einstein's equation for the viscosity of a suspension of spherical rigid particles. Hence, the Guth-Gold equation takes into account the effect of hydrodynamic reinforcement arising from the inclusion of rigid particles into the polymer matrix.

According to the MR equation, the plot of the reduced stress, $\sigma_{\text {red }}=\sigma / \lambda-\lambda^{-2}$, as a function of the inverse extension ratio, $\lambda^{-1}$, should yield a linear curve, from which the values of $C_{1}$ (intercept) and $C_{2}$ (slope) can be readily obtained. Figure 6a shows the stressstrain curves of IOC and OC containing nanocomposites, and Table 2 summarizes the results. As expected, EP-IOC exhibits remarkably higher stress at a certain strain (200 and 300\%) compared with pure EPDM gum compound and EP-OC. In the case of EPDM gum vulcanizate, the stress steadily increases with strain until the material fails. On the other hand, in EPDM nanocomposites, the overall nature of the stress-strain plot does not change much except for a significant increase in the elongation at break and the tensile strength (Figure 6a). A small upturn in the stress-strain plot can also be observed in the case of EP-IOC. The improvement in the mechanical properties is partially due to the higher degree of delamination of the clay layers into the rubber matrix, which allows the fillers to interact more intensely with the polymer because of the higher surface area. This result also supports the results obtained from XRD and cure studies.

The $\sigma / \lambda-\lambda^{-2}$ versus $1 / \lambda$ plots (called MR plots) of the EPDM-OC nanocomposites are shown in Figure 6b, and the calculated values of 

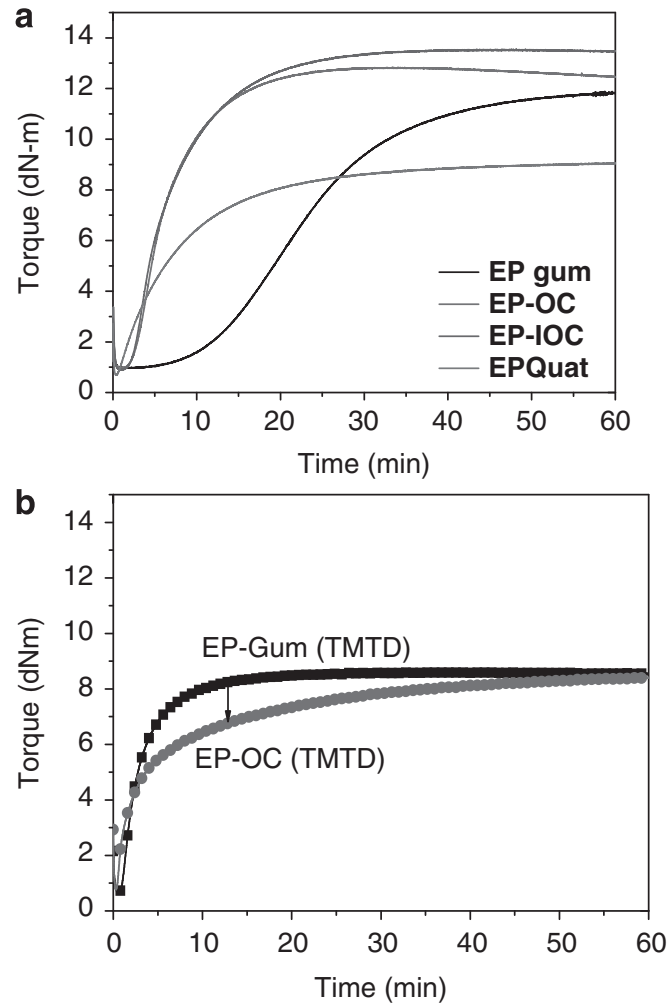

Figure 5 (a) Rheometric curing study of ethylene propylene diene terpolymer (EPDM) with different composition (see Table 1). (b) Development of curing torque of EPDM rubber with and without organoclay cured by tetramethyl thiuram disulfide (TMTD). The TMTD containing rubber formulation was 2 phr TMTD, 1 phr sulfur, 5 phr ZnO and 2 phr stearic acid.

$C_{1}$ and $C_{2}$ are tabulated in Table 3. The unfilled EPDM gum compound showed completely linear behavior between $\sigma / \lambda-\lambda^{-2}$ and $1 / \lambda$ at high strain. However, in the case of EP-OC and EPIOC, a small increase at high strain can be observed (Figure 6b), indicating a small tendency of strain-induced crystallization, which may be attributed to the presence of OC. In addition, the large content of QUAT and DIPDIS molecules at the polymer-filler interface favor the orientation of the polymer chains during stretching. ${ }^{40}$

There is a slight change in $C_{1}$ value that depends on the crosslink density and the modulus of the materials. The crosslink densities of the composites were also estimated from swelling experiments. The swelling percentage is the measurement of the degree of crosslinking, where a reduction in swelling indicates an increase of the crosslink density. Table 3 shows that the crosslink density increased with the addition of OC in the EPDM matrix. The value of crosslink density was even higher for the sample containing IOC. This observation is supported by the higher rheometric torque value obtained in the case of IOC containing the nanocomposite. The values of the crosslink density obtained from swelling experiments also corroborate the trend obtained from the $C_{1}$ values.

\section{Dynamic mechanical analysis}

The storage modulus $(\mathrm{G})$ of the samples is shown in Figure $7 \mathrm{a}$ for a wide temperature range: $-60{ }^{\circ} \mathrm{C}$ to $+60{ }^{\circ} \mathrm{C}$. The storage modulus is a quantitative measure of the stiffness or rigidity of a material. The figure shows that the storage modulus is higher in the case of EPDM filled with IOC at the rubbery plateau region in comparison with the
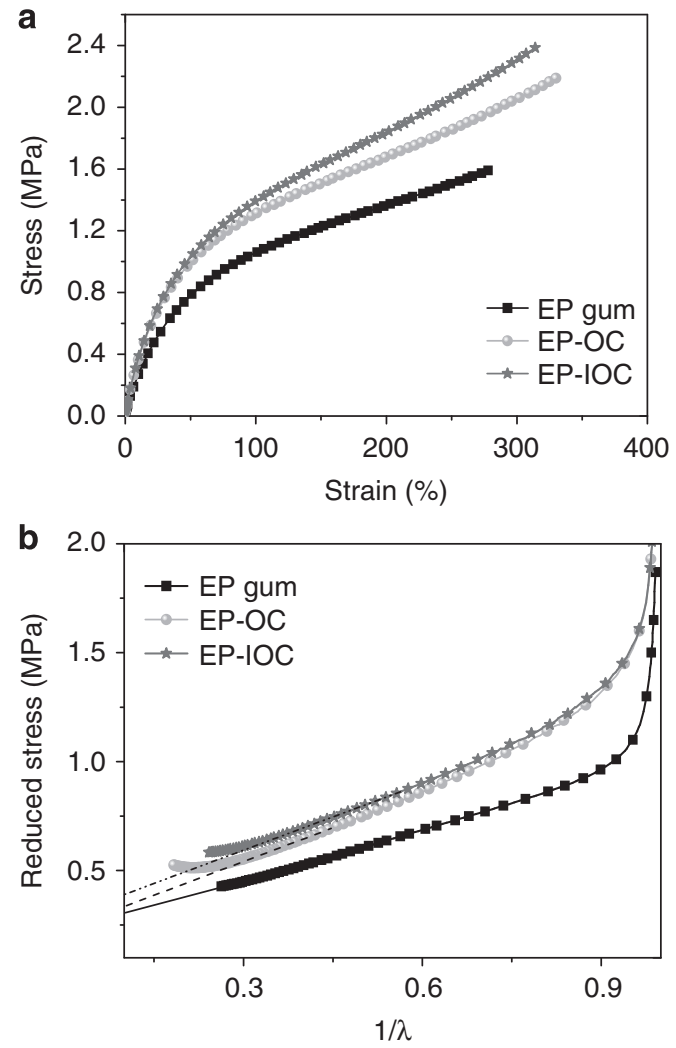

Figure 6 (a) Stress-strain diagrams of crosslinked ethylene propylene diene terpolymer (EPDM) rubber and (b) Mooney-Rivlin plots obtained from stress-strain experiments.

Table 2 Physical properties different EPDM rubber nanocomposites

\begin{tabular}{lcccc}
\hline Samples & TS (MPa) & M200 (MPa) & M300 (MPa) & EB (\%) \\
\hline EP gum & 1.61 & 1.42 & - & 270 \\
EP-OC & 2.38 & 1.63 & 2.01 & 390 \\
EP-IOC & 2.68 & 1.89 & 2.37 & 366 \\
\hline
\end{tabular}

Abbreviations: EB, elongation at break; EPDM, ethylene propylene diene terpolymer; IOC, intercalated organoclay; OC, organoclay; TS, tensile strength.

Table 3 Effect of preintercalation of DIPDIS on the values of $C_{1}$ and $c_{2}$ in EPDM-clay nanocomposites

\begin{tabular}{lccc}
\hline Samples & $\mathrm{C}_{1}(\mathrm{MPa})$ & $\mathrm{C}_{2}(\mathrm{MPa})$ & Crosslink density $\left(\mathrm{mol} \mathrm{cm}^{-3}\right)$ \\
\hline EP gum & 0.31 & 0.476 & $3.5 \times 10^{-5}$ \\
EP-OC & 0.33 & 0.472 & $3.6 \times 10^{-5}$ \\
EP-IOC & 0.37 & 0.473 & $4.1 \times 10^{-5}$ \\
\hline
\end{tabular}

Abbreviation: EPDM, ethylene propylene diene terpolymer.

EPDM gum compound. No significant change was observed in storage modulus at higher temperatures in the case of IOC and OC nanocomposites. The change in $\tan \delta$ with temperature $(\mathrm{T})$ is demonstrated in Figure 7b. A slight reduction of the $\tan \delta$ peak height was observed for IOC-containing vulcanizates. The DIPDIS molecules promote the intercalation of the EPDM molecular chains into the inter-gallery space of the clay more readily and attach more tightly to the surface of the clay. This process may constrain the mobility and flexibility of the rubber chains, leading to low $\tan \delta$ values. 

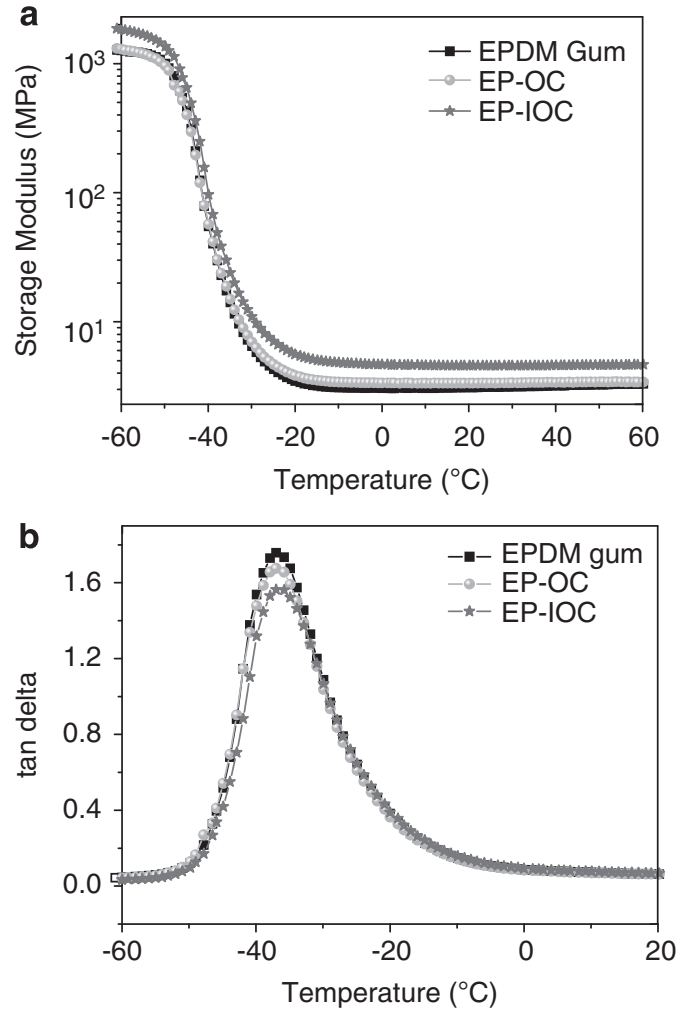

Figure 7 Dynamic mechanical properties of crosslinked ethylene propylene diene terpolymer (EPDM) rubber and nanocomposites (a) Storage modulus versus temperature and (b) $\tan \delta$ versus temperature.

\section{Thermogravimetric analysis}

The TGA curves for the EPDM-clay nanocomposites in nitrogen are shown in Figure 8. The data reveal that the loading of OC and the preintercalation of OC with DIPDIS molecules have prominent effects on the thermal stability of the resulting rubber nanocomposites. The temperature at $50 \%$ weight loss for unfilled EPDM gum vulcanizate is $492^{\circ} \mathrm{C}$. However, this temperature is further increased to $496{ }^{\circ} \mathrm{C}$ with the addition of 5 parts per hundred of rubber (phr) OC. The temperature at $50 \%$ weight loss for IOC is $500{ }^{\circ} \mathrm{C}$, which is even higher compared with those of both the unfilled and OC-containing EPDM nanocomposites. The increase of the thermal stability is attributed to the hindered diffusion of volatile decomposition products within the nanocomposites. Moreover, for the EP-IOC nanocomposites, a substantial portion of the macromolecular chain was entrapped in delaminated gallery space, which can delay the degradation behavior of the polymer chains.

\section{CONCLUSIONS}

EPDM-clay nanocomposites were successfully prepared by the preintercalation of organic accelerator molecules into the gallery gap of clay layers. The EPDM molecules were interlaced more readily when the organic accelerator molecules were present in the gallery space of the clay structure. XRD results showed that the silicate layers of the clay were successfully intercalated by the DIPDIS; that is, the basal spacing of the clay galleries expanded from 2.98 to $3.76 \mathrm{~nm}$. TEM was used to explore the morphology of the nanocomposites and proved that the nanocomposites were composed of a random distribution of intercalated and exfoliated aggregates throughout the rubber matrix. TGA showed that the incorporation of pre-IOC into the EPDM

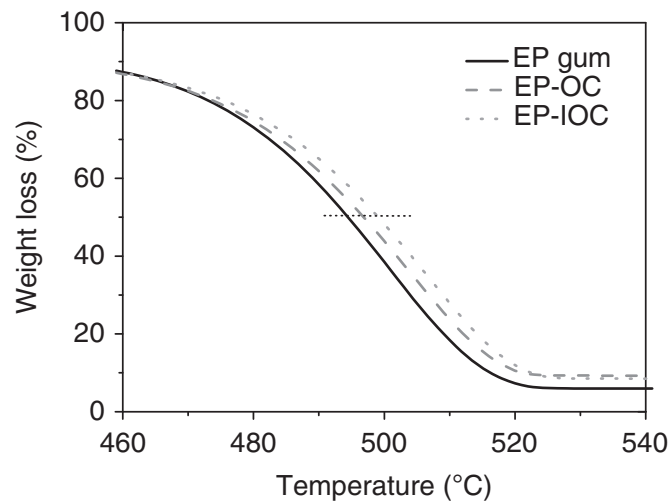

Figure $\mathbf{8}$ Thermogravimetric analysis of ethylene propylene diene terpolymer (EPDM)-activated clay nanocomposites.

matrix led to an apparent improvement in the thermal stability of the nanocomposites. However, the curing study showed that cure retardation, a typical behavior involving curative adsorption due to the filler surface, was not observed, though the clay was preintercalated with the organic accelerator. In addition, a cure synergism was observed between the DIPDIS and QUATs, as reflected in the fastcuring nature of this particular composite. These results are attributed to the significantly improved compatibility and strong interaction between the polar clay particles and the nonpolar molecular chains of EPDM. This work proves the multifunctional nature of the DIPDIS accelerator in the preparation clay-rubber nanocomposites.

\section{ACKNOWLEDGEMENTS}

We thank Mrs Juliane Meinl and Mrs Uta Reuter of Leibniz-Institut für Polymerforschung Dresden e.V. for XRD and TEM analysis, respectively.

1 Vaia, R. A., Ishii, H. \& Giannelis, E. P. Synthesis and properties of two-dimensional nanostructures by direct intercalation of polymer melts in layered silicates. Chem. Mater. 5, 1694-1696 (1993).

2 Okada, A. \& Usuki, A. The chemistry of polymer-clay hybrids. Mater. Sci. Eng. C 3, 109-115 (1995).

3 Jia, Q. X., Wu, Y. P., Xu, Y. L., Mao, H. H. \& Zhang, L. Q. Combining in-situ organic modification of montmorillonite and the latex compounding method to prepare highperformance rubber-montmorillonite nanocomposites. Macromol. Mater. Eng. 291, 218-226 (2006).

4 Ray, S. S. \& Okamoto, M. Polymer/layered silicate nanocomposites: a review from preparation to processing. Prog. Polym. Sci. 28, 1539-1641 (2003).

5 Lebaron, P. C. \& Pinnavaia, T. J. Clay nanolayer reinforcement of a silicone elastomer. Chem. Mater. 13, 3760-3765 (2001).

6 Hwang, W. G., Wei, K. H. \& Wu, C. M. Mechanical, thermal, and barrier properties of NBR/organosilicate nanocomposites. Polym. Eng. Sci. 44, 2117-2124 (2004).

7 Park, J. \& Jana, S. C. Adverse effects of thermal dissociation of alkyl ammonium ions on nanoclay exfoliation in epoxy-clay systems. Polymer 45, 7673-7679 (2004).

8 Ganguly, A., Bhowmick, A. K. \& Li, Y. Insights into montmorillonite nanoclay based ex situ nanocomposites from SEBS and modified SEBS by small-angle X-ray scattering and modulated DSC studies. Macromolecules 41, 6246-6253 (2008).

9 Marras, S. I., Tsimpliaraki, A., Zuburtikudis, I. \& Panayiotou, C. Morphological, thermal, and mechanical characteristics of polymer/layered silicate nanocomposites: the role of filler modification level. Polym. Engg. Sci. 49, 1206-1217 (2009).

10 Gilman, J. W., Awad, W. H., Davis, R. D., Shields, J., Harris, R. H. C. Jr, Davis, A., Morgan, B., Sutto, T. E., Callahan, J., Trulove, P. C. \& DeLongr, H. C. Polymer/layered silicate nanocomposites from thermally stable trialkylimidazolium-treated montmorilIonite. Chem. Mater. 14, 3776-3785 (2002).

11 Livi, S., Duchet-Rumeau, J., Pham, T. N. \& Gerard, J. FA comparative study on different ionic liquids used as surfactants: Effect on thermal and mechanical properties of highdensity polyethylene nanocomposites. J. Colloid Interface Sci. 349, 424-433 (2010).

12 Shanmugharaj, A. M., Rhee, K. Y. \& Ryu, S. H. Influence of dispersing medium on grafting of aminopropyltriethoxysilane in swelling clay materials. J. Colloid Interface Sci. 298, 854-859 (2006). 
13 Kim, E. S., Shim, J. H., Woo, J. Y., Yoo, K. S. \& Yoon, J. S. Effect of the silane modification of clay on the tensile properties of nylon 6/clay nanocomposites. J. Appl. Polym. Sci. 117, 809-816 (2010).

14 Chou, C. C., Chiang, M. L. \& Lin, J. J. Unusual intercalation of cationic smectite clays with detergent-ranged carboxylic ions. Macromol. Rapid Commun. 26, 1841-1845 (2005).

15 Das, A., Stöckelhuber, K. W., Jurk, R., Jehnichen, D. \& Heinrich, G. A general approach to rubber clay nanocomposites: intercalation of stearic acid. Appl. Clay Sci. 51, 117-125 (2011).

16 Das, A., Mahaling, R. N., Stöckelhuber, K. W. \& Heinrich, G. Reinforcement and migration of nanoclay in polychloroprene/ethylene propylene diene monomer rubber blends. Comp. Sci. Technol. 71, 276-281 (2011).

17 Das, A., Stöckelhuber, K. W., Rooj, S., Wang, D. Y. \& Heinrich, G. Synergistic effects of expanded nanoclay and carbon black on natural rubber compounds. Kautsch. Gummi Kunst. 63, 296-302 (2010).

18 Rosenberg, P. \& Coon, J. M. Potentiation between cholinesterase inhibitors. Proc. Soc. Exp. Biol. Med. 97, 836-839 (1958).

19 Neth. Pat. 6, 507, 603 (1965), assigned to Shell Research.

20 Pishchimika, P. S. Zh. Russk. Fizkhim. Obshch. 56, 11 (1925).

21 Romieux, C. J. \& Ashley, K. D. Di-thiophosphate compounds. US Patent 19496291934

22 Pimblott, J. G., Scott, G. \& Stuckey, J. E. Bis(diisopropyl) thiophosphoryl disulfide in cis-1,4-polyisoprene vulcanization reactions. I. As a sulfur donor. J. Appl. Polym. Sci. 19, 865-877 (1975).

23 Das, A., De, D., Naskar, N. \& Debnath, S. C. Effect of vulcanization technique on the physical properties of silica-filled EPDM rubber. J. Appl. Polym. Sci. 99, 1132-1139 (2006).

24 Das, A., Ghosh, A. K., Pal, S. \& Basu, D. K. The role of thiophosphoryl disulfide on the co-cure of CR-EPDM blends. Polym. Adv. Technol. 15, 197-208 (2004).

25 Das, A., Ghosh, A. K. \& Basu, D. K. Evaluation of physical and electrical properties of chloroprene rubber and natural rubber blends. Kautsch. Gummi. Kunstst 58, 230-238 (2005).

26 Das, A. \& Basu, D. K. Evaluation of physical and dielectric properties of chloroprene and styrene butadiene rubber blends. J. Appl. Polym. Sci. 96, 1492-1504 (2005).
27 Das, A., Debnath, S. C., De, D., Naskar, N. \& Basu, D. K. The role of thiophosphoryl disulfide on the co-cure of CR-EPDM blends: Effect of white fillers. Polym. Adv. Technol. 15, 551-559 (2004).

28 Das, A., Naskar, N. \& Basu, D. K. Thiophosphoryl disulfides as crosslinking agents for chloroprene rubber. J. Appl. Polym. Sci. 91, 1913-1919 (2004).

29 Bergaya, F., Theng, B. K. G. \& Lagaly, G. (eds). Handbook of Clay Science, 1st edn (Elsevier Science, Amsterdam, The Netherlands, 2006).

30 Flory, P. J. \& Rehner, J. Crosslink density equation. J. Chem. Phys. 11, 5120 (1943).

31 Mandal, S. K., Dutta, R. N., Das, P. K. \& Basu, D. K. Studies on the reaction of bis(diisopropyl) thiophosphoryl disulfide with silica in the vulcanization of NR. J. Appl. Polym. Sci. 35, 987-994 (1988).

32 Ghosh, A. K., Debnath, S. C., Naskar, N. \& Basu, D. K. NR-EPDM covulcanization: a novel approach. J. Appl. Polym. Sci. 81, 800-808 (2001).

33 Morlat-Therious, S., Fanton, E., Tomer, N. S., Rana, S., Singh, R. P. \& Gardette, J. L. Photooxidation of vulcanized EPDM/montmorillonite nanocomposites. Polym. Degrad. Stab 91, 3033-3039 (2006).

34 Lagaly, G., Barrer, R. M. \& Goulding, K. Clay-organic interactions [and discussion]. Phil. Trans. R. Soc. Lond. A 311, 315-332 (1984).

35 Lagaly, G. \& Dékany, I. Adsorption on hydrophobized surfaces: clusters and selforganization. Adv. Colloid Interface Sci. 114-115, 189-204 (2005).

36 Usuki, A., Tukigase, A. \& Kato, M. Preparation and properties of EPDM-clay hybrids. Polymer 43, 2185-2189 (2002).

37 Mooney, M. A theory of large elastic deformation. J. Appl. Phys. 11, 582-592 (1940).

38 Rivlin, R. S. \& Saunders, D. W. Large elastic deformation of isotropic materials VII. Experiments on the deformation of rubber. Phil. Trans. R. Soc. Lond. A 243, 251-298 (1951).

39 Guth, E. \& Gold, O. On the hydrodynamical theory of the viscosity of suspensions. Phys. Rev 53, 322-325 (1938).

40 Gonzalez, J. C., Verdejo, R., Toki, S., Hsiao, B. S., Giannelis, E. P. \& López-Manchado, M. A. Real-time crystallization of organoclay nanoparticle filled natural rubber under stretching. Macromolecules 41, 2295-2298 (2008). 